\title{
Biosafety Evaluation and Quantitative Determination of Poly(hexamethylene biguanide) (PHMB) Coated on Cellulosic Fabrics by Kubelka-Munk Equation
}

\section{Wen-Yi Wang}

The Hong Kong Polytechnic University

Jia-Chi Chiou

The Hong Kong Polytechnic University

Wan-Xue Chen

The Hong Kong Polytechnic University

Jia-Li Yu

The Hong Kong Polytechnic University

Chi-wai Kan ( $\nabla$ tccwk@polyu.edu.hk)

The Hong Kong Polytechnic University

\section{Research Article}

Keywords: Kubelka-Munk equation, colour strength, cationic finishing agents, cellulosic fabrics, quantitative determination, biosafety evaluation

Posted Date: February 9th, 2021

DOI: https://doi.org/10.21203/rs.3.rs-174148/v1

License: (c) (i) This work is licensed under a Creative Commons Attribution 4.0 International License.

Read Full License 
1 Biosafety evaluation and quantitative 2 determination of poly(hexamethylene 3 biguanide) (PHMB) coated on cellulosic fabrics 4 by Kubelka-Munk equation

Wen-Yi Wang', Jia-Chi Chiou², Wan-Xue Chen², Jia-Li Yu \& Chi-Wai Kan ${ }^{1}{ }^{1}$ *

${ }^{I}$ Institute of Textiles and Clothing, the Hong Kong Polytechnic University, Hung Hom, Kowloon, Hong Kong, China.

${ }^{2}$ Department of Applied Biology and Chemical Technology, The Hong Kong Polytechnic University, Hung Hom, Kowloon, Hong Kong, China.

*Corresponding author: tccwk@polyu.edu.hk

Abstract

It is a challenge to determine the quantity of cationic finishing agents on the surface of cellulosic fabrics. Herein, we report a direct and feasible method by KubelkaMunk equation to quantify the cationic poly (hexamethylene biguanide) hydrochloride (PHMB) adsorbed onto cotton fabrics based on the principle of formation of a stable blue dye between PHMB and bromophenol blue sodium (BPB). The adsorption of PHMB onto cotton fabrics was first investigated and the maximum adsorption of PHMB was found to be around $8 \mathrm{mg}$ per gram of cotton fabric. After being dyed with BPB, colour strength shows a positive correlation with PHMB at low concentrations $(<2400 \mathrm{mg} / \mathrm{L})$. A linear relationship with a high correlation $\left(C(\mathrm{PHMB})=(K / S-0.7411) / 3.4517, \mathrm{R}^{2}=0.9983\right)$ was thus established between colour strength and PHMB concentration. However, this equation should fulfill four requirements for quantifying PHMB: (1) the distribution of PHMB on the surface of cellulosic fabric should be in the form of a monolayer with the content less than $5.3 \mathrm{mg} / \mathrm{g}$; (2) an excess of BPB dyebath should be applied; (3) the dyeing should come to equilibrium; and (4) the fabrics should be evenly dyed. Moreover, MTT assay results indicate that excess PHMB coated on cotton fabrics can cause cytotoxicity and the quantity of PHMB should not exceed $4.62 \mathrm{mg}$ per gram of cotton fabrics for the purpose of biosafety. The sample can be considered noncytotoxic if the $K / S$ value is lower than 13.2 after dyeing with BPB.

Keywords: Kubelka-Munk equation; colour strength; cationic finishing agents; cellulosic fabrics; quantitative determination; biosafety evaluation

Author contributions

Conceptualizaiton: Wen-Yi Wang, Chi-Wai Kan; Methodology: Wen-Yi Wang, JiaChi Chiou, Wan-Xue Chen, Jia-Li Yu; Formal analysis and investigation: WenYi Wang, Chi-Wai Kan; Writing- original draft preparation: Wen-Yi Wang; Writing- review and editing: Chi-Wai Kan; Funding acquisition: Chi-Wai Kan; Resources: Chi-Wai Kan, Jia-Chi Chiou; Supervision: Chi-Wai Kan. 
Cationic surfactants are predominantly nitrogenous polymers such as guanidines and quaternary ammonium compounds (QACs) with positively charged surface-active moieties on the hydrophilic end. Cationic surfactants find wide applications in textile finishing primarily as fabric softeners, antistatic and antimicrobial agents (Sivaramakrishnan 2013; Kosswig 2000). Finishing agents used as fabric softeners can improve softness and wearability of the fabric, and reduce the static electricity built-up on the surface of fibres if used as antistatic agents (Beal et al. 1990; Agarwal et al. 2011). Antimicrobial agents are used in textile finishing not only to prevent deterioration of fibre strength and quality due to microbial colonization by insects, fungi and micro-organisms but also to circumvent cross-contamination and nosocomial infections (Gao et al. 2019, 2021). However, prolonged exposure to these chemicals, particularly in the case of overuse and even abuse of cytotoxic antibacterial agents, can cause skin irritation and damage because of the destroyed lipid membrane that serve as the external protective layer of the skin (Kosswig 2000). Therefore, determination of these cationic finishing agents coated on the fabrics is of high importance because that is necessary to ensure compliance with safety regulations and production standards in the public interest. To the best of our knowledge, only qualitative methods have been reported for identifying the existence of cationic surfactants in cellulosic textile fabrics (Fan 2005). A simple, direct, and efficient method for determining the quantity of cationic surfactants adsorbed onto the cellulosic fabrics does not seem to have been proposed hitherto, though it is highly imperative.

Cationic finishing agents are generally used in finishing of textile fabrics in the form of a multicomponent finishing solution or suspension mixed with inorganic salts, polymeric binders or other additives such as emulsifiers and dispersants by conventional exhaust, pad-dry-cure processes, spraying or foam finishing method (Yuan and Cranston 2008; Gargoubi et al. 2016). This makes it difficult to quantify the agents coated on cellulosic fabrics. Some surface analytical techniques such as scanning electron microscopy (SEM), X-ray photoelectron spectroscopy (XPS), Fourier Transform Infrared Spectroscopy (FTIR) and mass spectrometry (ToF-SIMS) are often used to qualitatively study the presence of cationic finishing agents on the fabrics (Brunon et al. 2011; Wang et al. 2020; Mitchell et al. 2005). Spectrophotometry provides an indirect method to quantify cationic finishing agents based on extraction of ion associates formed between cationic agents and anionic dyes such as disulfine blue and ethyl orange (Li and Zhao 2004; Motomizu and Gao 1994). Relatively more sophisticated chromatographic approaches such as gas chromatography (GC), gradient gel-permeation chromatography (GPC) and highperformance liquid chromatography (HPLC) are precise methods to quantify cationic finishing agents in fabrics (Lucas et al. 2009; Masadome et al. 2018). Recently, various novel methods with high sensitivity such as glucose oxidase enzymatic reaction analytical method and Lactone-rhodamine B-based 90 fluorescence optode technique have been introduced to quantify 91 poly (hexamethylene biguanide) hydrochloride (PHMB) in the solution used for 92 contact lens (Funaki et al. 2020; Masadome et al. 2018; Uematsu et al. 2019).

93 However, these analytical methods are primarily suitable for trace analysis 94 of cationic agents in aqueous, such as industrial wastewater and contact lens solution, and are incapable of quantifying cationic surfactants on the textile 
fabrics.

Bromophenol blue (BPB) is a kind of triphenylmethane dye which has been extensively used as laboratory acid-base indicator and biological stain for proteins and nucleic acids ( $\mathrm{Li}$ et al. 2019; Wang et al. 2017). Anionic BPB can be complexed with cationic surfactants at room temperature ascribed to electrostatic attraction, leading to formation of water-insoluble and stable blue complex dyes (Sheiham and Pinfold 1969; Colichman 1947). A more recent study on the application of BPB in dyeing of cotton fabric treated with cationic finishing agents was reported by our group (Wang and Kan 2020), in which the antibacterial agent PHMB was first coated on the fabric and then the fabric was dyed with BPB solution at room temperature without use of any inorganic salts. The dyed fabrics showed excellent colour levelness and fastness to rubbing and washing, and the colour strength was found controllable and highly dependent upon concentration of BPB dyebath and quantities of coated PHMB.

Colour strength of dyed fabrics is customarily expressed as $K / S$ value, where $K$ and $S$ are the absorption and scattering coefficients of the dyed sample, respectively. Absorption coefficient $K$ is primarily dependent on the dyestuff whereas scattering coefficient $S$ is determined by the substrate. $K / S$ value can be calculated from the reflectance value $(R)$ according to Kubelka-Munk equation (Eq. (1)) (Becerir 2005; Tang et al. 2019).

$$
\mathrm{K} / \mathrm{S}=\frac{(1-R)^{2}}{2 R}
$$

$K / S$ value has been commonly used to quantitatively evaluate the quantity of dye on the fabric at the maximum absorption wavelength. $K / S$ value increases with dye content of the fabric increasing. The peak height in the $K / S$ spectrum (plotted by Eq. (1)) is proportional to the quantity of dye in the substrate, and the functional relationship is as given in Eq. (2) (Ahmed et al. 2006; Khatri et a1. 2014).

$$
\mathrm{K} / \mathrm{S}=\mathrm{A} \cdot \mathrm{C}
$$

Where $A$ is a constant equal to the gradient of the plot of $K / S$ versus dyestuff quantity in the substrate which depends on the absorption coefficient of the dyestuff, dyeing conditions and textile substrates; $C$ is the dyestuff quantity in the textile substrate. Theoretically, $A$ is independent of concentration $C$. Therefore, the dye quantity can be obtained from Eq. (2), which equals to the quantity of cationic surfactants coated in the fabric substrate due to stoichiometric reaction (Eq. (3)).

$$
C(\text { dye })=C(P H M B)=(K / S) / A
$$

Here we are inspired to quantify the cationic finishing agents on the cellulosic fabrics by measuring the colour strength after dyeing with BPB. On the other hand, biosafety properties such as skin irritation and cytotoxicity of treated fabrics are closely associated with the quantity of cationic agents on the fabrics, which may also be manifested by colour strength. In the present study, PHMB is exemplified to validate the assumption that quantifies the cationic agents on the fabrics using Kubelka-Munk equation. The correlation between PHMB content on the fabrics and colour strength dyed with BPB dyebath, as well as biosafety properties, was investigated in detail. 


\section{Materials}

144 Plain weave $100 \%$ cotton fabric (40 ends per inch in warp and weft; fabric 145 weight $175 \mathrm{~g} / \mathrm{m}^{2}$ ) was used. The fabric was initially cleaned in an aqueous 146 solution with $2 \mathrm{~g} / \mathrm{L}$ sodium carbonate (obtained from Sigma-Aldrich, St. Louis, $147 \mathrm{M} 0, \mathrm{USA})$ and $2 \mathrm{~g} / \mathrm{L}$ non-ionic detergent (C13-oxoalcoholethoxylates (7E0), 148 supplied by SDC Enterprises Limited, Holmfirth, UK) at $60{ }^{\circ} \mathrm{C}$ for 30 minutes 149 to remove impurities. Afterwards, the fabric was thoroughly rinsed with tap 150 water and dried at room temperature.

151 Dulbecco modified eagle medium (DMEM) without phenol red, DMEM, newborn calf 152 serum (NBS), 0.5\% Trypsin-EDTA and phosphate buffer saline (PBS) were 153 purchased from Thermo Fisher (Waltham, Massachusetts, USA). 154 Poly(hexamethylene biguanide) (PHMB, 20\% w/v aqueous solution), the mode1 155 cationic antibacterial agent, was supplied by Breakthrough Textiles Co., Ltd 156 (Taipei, Taiwan). Bromophenol blue (BPB) sodium salt was obtained from Sigma157 Aldrich (St. Louis, M0, USA).

\section{PHMB coating on cotton fabrics}

159 Fabric samples $(10 \times 20 \mathrm{~cm})$ were immersed in PHMB solution of different 160 concentrations overnight for complete exhaustion with a liquor ratio of $30: 1$. 161 The samples were then withdrawn and cured at $150{ }^{\circ} \mathrm{C}$ for 3 minutes. Afterwards, 162 the liquor was retained for concentration determination by UV-vis 163 spectrophotometry. Fabric samples treated with different concentrations of 164 PHMB were labelled as $\mathrm{P}^{\sim}{ }^{\mathrm{P} 15}$, respectively, as shown in Table 1.

165 Table 1 Sample list for cotton fabrics coated with different concentrations of 166 PHMB

\begin{tabular}{cccccc}
\hline $\begin{array}{c}\text { Sample } \\
\text { no. : }\end{array}$ & $\begin{array}{c}\text { PHMB conc. } \\
(\mathrm{mg} / \mathrm{L})\end{array}$ & $\begin{array}{c}\text { Sample } \\
\text { no. }:\end{array}$ & $\begin{array}{c}\text { PHMB conc. } \\
\text { (mg/L) }\end{array}$ & $\begin{array}{c}\text { Sample } \\
\text { no. : }\end{array}$ & $\begin{array}{c}\text { PHMB conc. } \\
\text { (mg/L) }\end{array}$ \\
\hline P1 & 100 & P6 & 1600 & P11 & 4000 \\
P2 & 200 & P7 & 2000 & P12 & 5000 \\
P3 & 400 & P8 & 2400 & P13 & 6000 \\
P4 & 800 & P9 & 3000 & P14 & 8000 \\
P5 & 1200 & P10 & 3600 & P15 & 10000 \\
\hline
\end{tabular}

\section{Adsorption equilibrium studies}

Concentration of exhausted PHMB solution was measured using a UV-2401PC UVvisible spectrophotometer at $\lambda \max$ of PHMB by the calibration curve. The amount of adsorption at equilibrium qe (mg/g) was calculated by Eq. (4).

$$
q_{e}=\frac{(C i-C e) V}{m}
$$

172 Where $C_{i}$ and $C_{e}$ are the initial and equilibrium concentration in $\mathrm{mg} / \mathrm{L}$ of $\mathrm{PHMB}$ 173 before and after exhaustion; $V$ is the volume of PHMB solution (L); $m$ is the 174 mass of applied cotton fabric (g).

\section{Dyeing procedure}

176 BPB solution (500 $\mathrm{mg} / \mathrm{L})$ was initially prepared and stored in an amber 177 laboratory bottle prior to dyeing. The dyeing was performed by immersing the 

a sealed beaker, withdrawn after 30 minutes and then rinsed with tap water

180 to remove unfixed dyes. Finally, the dyed samples were air-dried in the fume 181 hood.

182 Colour strength measurement

183 After dyeing, colour strength $(K / S)$ of BPB-dyed samples was measured for visible wavelength of 400 to $700 \mathrm{~nm}$ by using a spectrophotometer GretagMacbeth Color Eye 7000A spectrophotometer. Parameters were small aperture and D65 daylight with a $10^{\circ}$ standard observer. Each sample was folded twice to provide a total of four layers of material. Three measurements at different locations for each specimen were randomly conducted. The colour strength $(K / S)$ was calculated according to the Kubelka-Monk equation (Eq. (1)).

\section{In vitro cytotoxicity evaluation}

In vitro cytotoxicity of PHMB coated cotton fabrics was evaluated by MTT assay in accordance with the standard IS0 10993-5:2009(E) using commercially available fibroblast (NIH3T3, ATCC CRL-1658; the American Type Culture Collection, Manassas, VA, USA). Samples of PHMB-coated cotton fabrics were cut into square shape $(4 \times 4 \mathrm{~mm})$, sterilized by UV radiation for 3 hours on both sides in a biological safety cabinet, and then extracted with the culture medium of Dulbecco' s Modified Eagle' s Medium (DMEM, $1 \mathrm{~mL}$ ) at $37^{\circ} \mathrm{C}$ for 24 hours. NIH3T3 was cultured in 12 mL DMEM with Newborn Calf Serum (NBS, 10\%) at $37^{\circ} \mathrm{C}$ and $5 \%$ carbon dioxide for 72 hours. The culture medium was replaced with fresh medium every 24 hours. Then, the cells were transferred into a 96-we11 plate with the seeding number of 30000 per well and allowed to grow in fresh medium for 24 hours. Afterwards, the medium was removed, and the cells were rinsed by PBS. The extraction $(100 \mu \mathrm{L})$ was added into the cells and incubated at $37^{\circ} \mathrm{C}$ and $5 \%$ carbon dioxide for 24 hours. The DMEM (without phenol red) and $2 \%$ Triton (in DMEM) were used as negative and positive control, respectively. Next, the cells were centrifuged at $1500 \mathrm{rpm}$ for 5 minutes with the S2096 rotor (Beckman Coulter, Indianapolis, IN, USA). Then, the

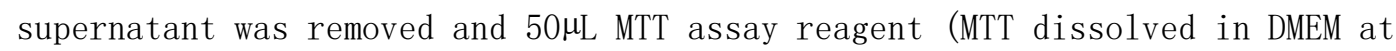
$1 \mathrm{mg} / \mathrm{mL}$ and filtered to sterilize) was added. After 2 hours, MTT reagent was

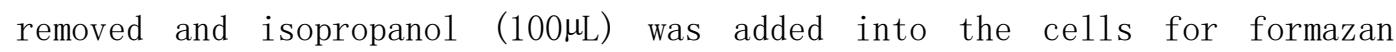
extraction for 10 minutes. Then the spectrophotometric analysis of extracted formazan was conducted by a microplate reader (CLARIOstar, BMGLabtech, Offenburg, Germany) at $570 \mathrm{~nm}$. Cytotoxicity was expressed as the ratio of the cell viability of each treatment to the maximum cell viability of the negative control.

\section{Results and discussion}

\section{Calibration curve of PHMB solution}

PHMB has high solubility ( $>40 \% \mathrm{w} / \mathrm{w})$ in water in the form of micelle. Fig. 1 (a) shows absorbance of diluted PHMB solution as a function of wavelength over the ultraviolet-visible spectrum. Clearly, PHMB shows no absorption in $\pi-\pi *$ transition of $-\mathrm{C}^{-\mathrm{NH}^{-}}$groups (De Paula et al. 2011). In this study, 
the characteristic peak at $235 \mathrm{~nm}$ was used to establish a calibration curve based on the Beer-Lambert law (Fig. 1(b)). A high correlation $\left(\mathrm{R}^{2}=0.9996\right)$

226 between the absorbance and PHMB concentration ranging from 4 to $20 \mathrm{mg} / \mathrm{L}$ was 227 obtained.
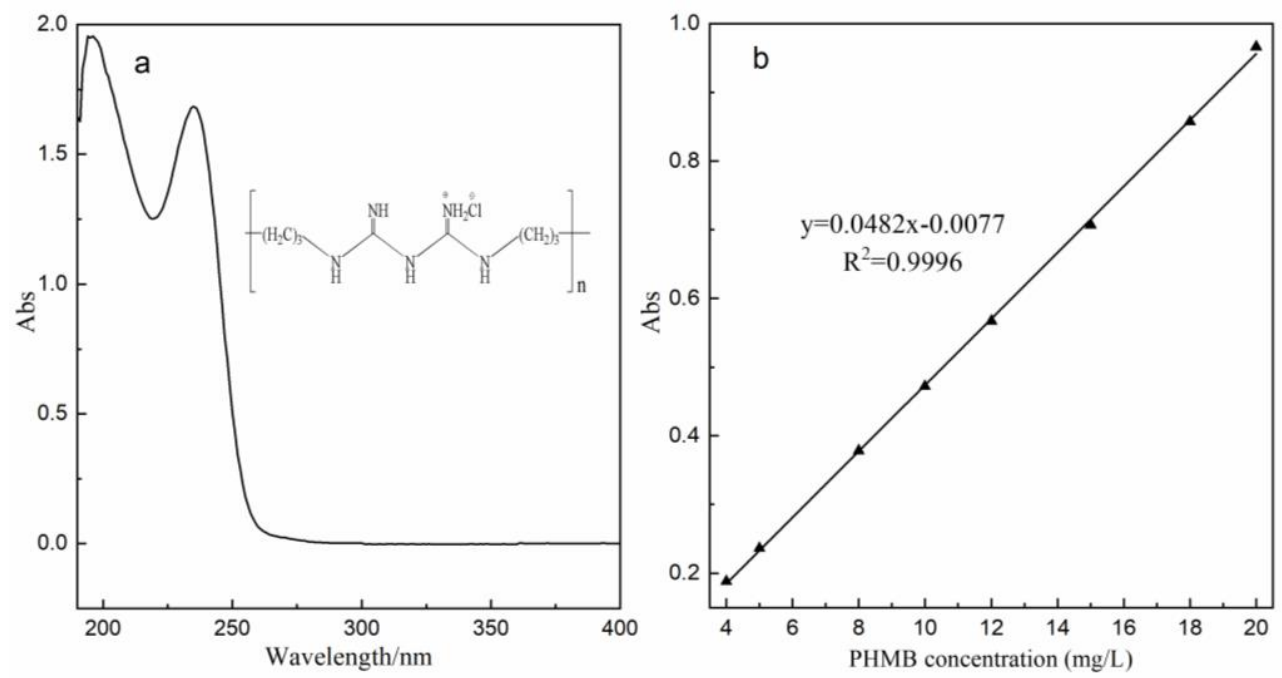

229 Fig. 1 The maximum absorbance of PHMB solution over the UV-vis spectrum (a); and the calibration curve of PHMB solution established at $235 \mathrm{~nm}$ (b)

\section{Adsorption of PHMB on cotton fabric}

232 A previous study has demonstrated that adsorption of PHMB on cellulosic fibres 233 is concentration-dependent and has characteristics of both Langmuir and 234 Freundlich isotherms attributed to a combination of electrostatic attraction 235 and hydrogen-bonding forces between PHMB and the carboxylic acid groups of 236 cellulose (Blackburn RS et al. 2006; Waggerg et al. 1988). This explains the good affinity and durability of PHMB-coated antibacterial cotton fabrics. The present study first investigated the adsorption of PHMB on cellulosic fabrics to establish the relationship between PHMB content adsorbed on cotton fabrics and the colour strength after dyeing in BPB dyebath. Fig. 2 displays the quantity of PHMB adsorbed by cotton fabrics based on UV-vis spectrophotometric analysis. As can be clearly seen, the higher the initial concentration of PHMB applied, the higher is the amount of PHMB adsorbed by cotton fabrics. The amount of adsorbed PHMB first increases sharply from $100 \mathrm{mg} / \mathrm{L}$ to 5000 $\mathrm{mg} / \mathrm{L}$, and then it has a flattened region up to $10000 \mathrm{mg} / \mathrm{L}$, as the initial concentration of PHMB increases. This suggests that a higher initial concentration of PHMB solution $(>5000 \mathrm{mg} / \mathrm{L})$ fails to enhance the adsorption 249 of PHMB under the fixed exhaustion duration. The maximum quantity of PHMB at equilibrium adsorption is around $8 \mathrm{mg}$ per gram of cotton fabric. 


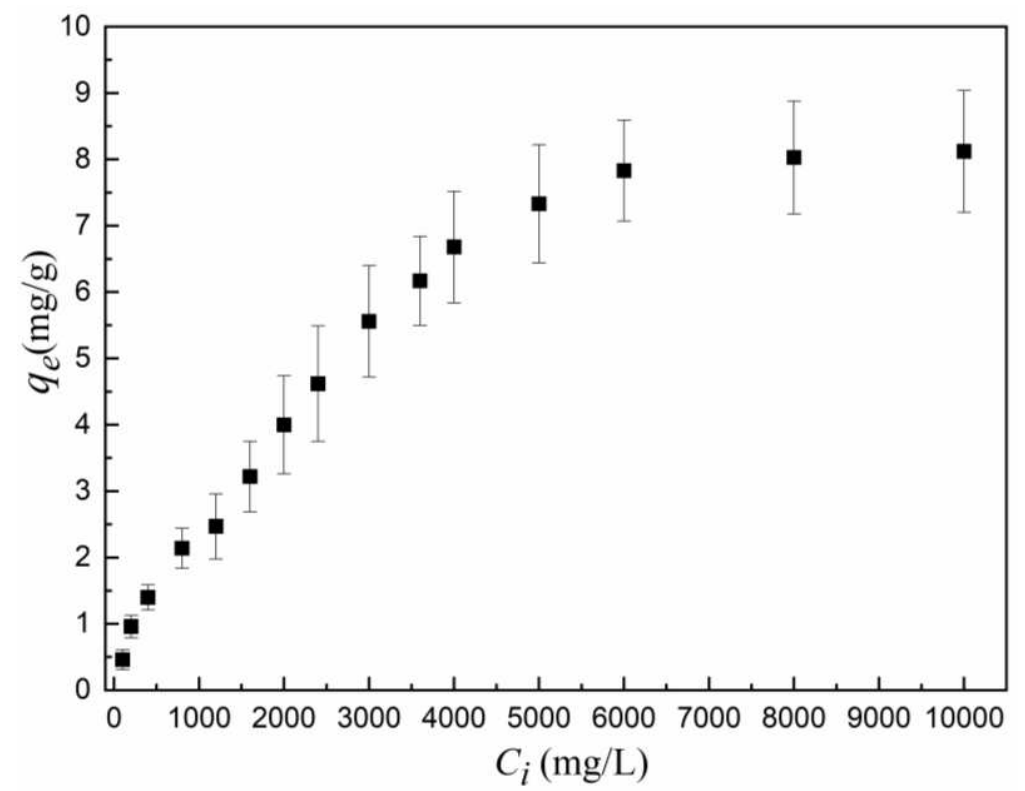

Fig. 2 Adsorption of PHMB onto the cotton fabric with concentration ranging from $252100 \mathrm{mg} / \mathrm{L}$ to $10000 \mathrm{mg} / \mathrm{L}$

\section{Colour strength analysis}

254 Fig. 3 presents the appearance of PHMB-treated cotton fabrics after dyeing 255 with excess BPB solution $(500 \mathrm{mg} / \mathrm{L})$. Clearly, the blue shade is achieved and colour depth shows gradient from light to dark as PHMB concentration increases. A11 samples exhibited a similar pattern and there was no shift in the peak of colour strength curves (Fig. 4). The maximum band observed in the visible range was at $600 \mathrm{~nm}$. Colour strength is basically proportional to the initially applied PHMB concentrations, particularly for lower concentrations of PHMB. A distinct increase was seen in samples treated with less than 2400 $\mathrm{mg} / \mathrm{L}$ of PHMB (P1-P8), and with PHMB concentration rising to $10000 \mathrm{mg} / \mathrm{L}$, colour strength shows a slow growth and overlaps with each other in the maximum peak of curves. This suggests that colour strength is highly dependent on the initial PHMB concentration, to be exact, depends on the quantity of PHMB adsorbed by the fabrics. Next, the relationship of colour strength with the adsorbed PHMB on the fabrics is discussed as below.

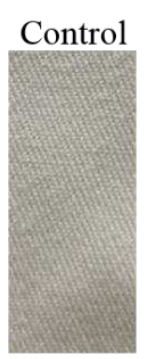

P8

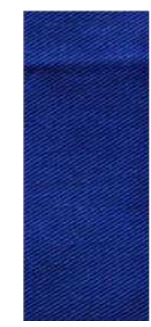

P1

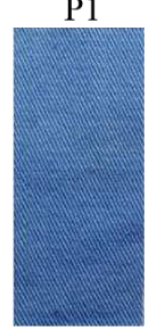

P9

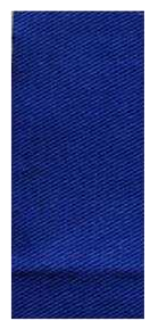

P2

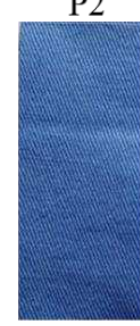

$\mathrm{P} 10$

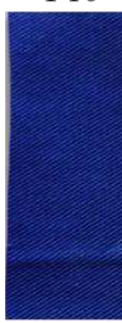

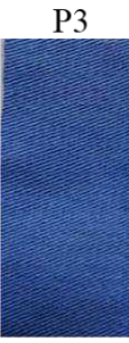

P11

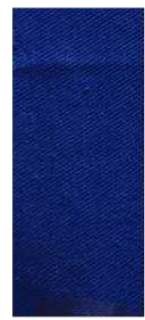

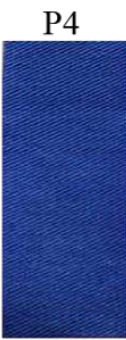

$\mathrm{P} 12$

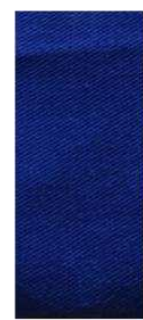

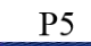

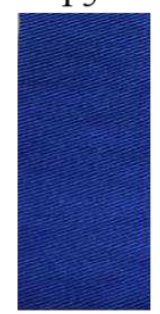

P13

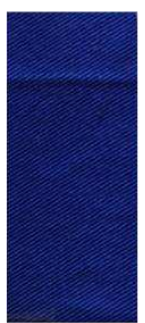

P6

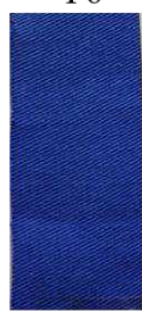

P14

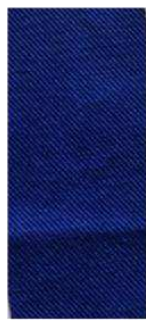

P7

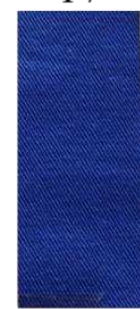

P15

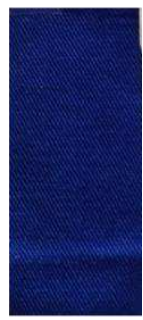

269 Fig. 3 Colour shades of PHMB-treated cotton fabrics after dyed with BPB dyebath 


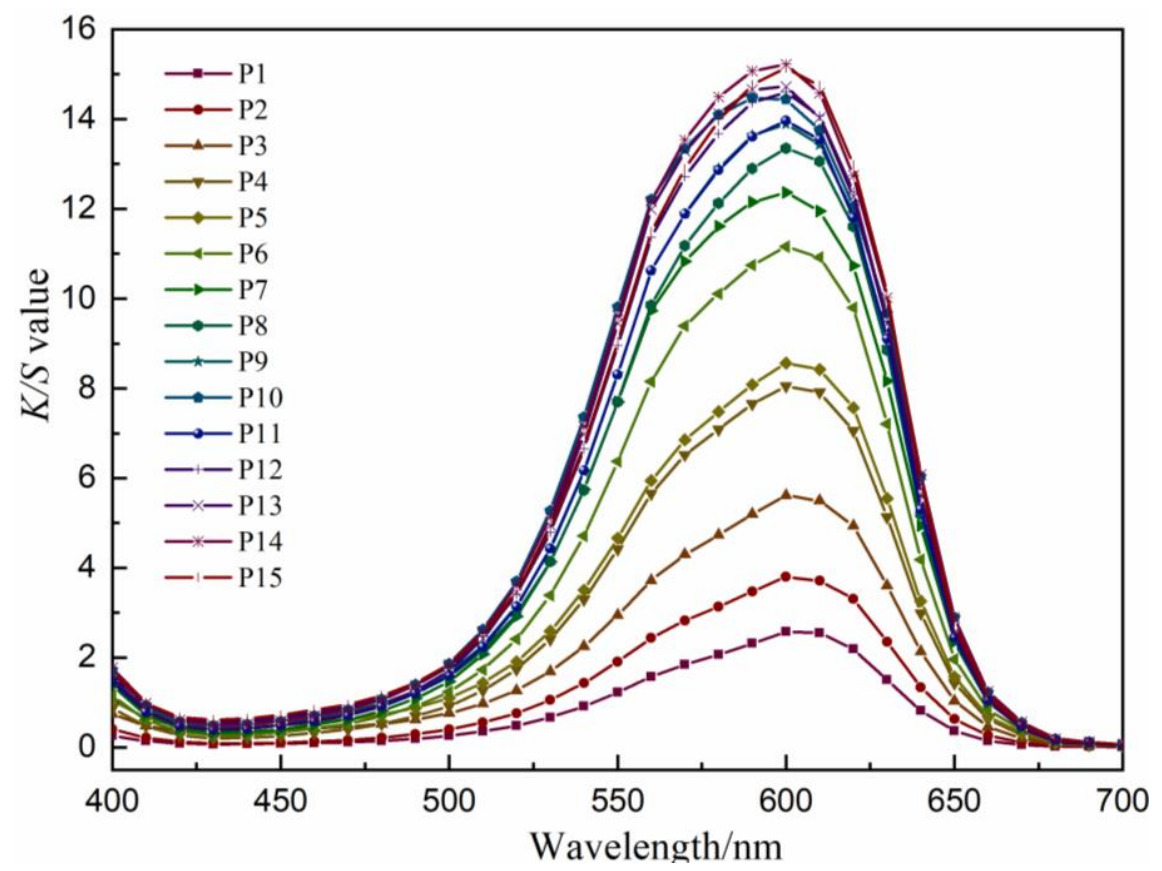

Fig. 4 Colour strength curves of cotton fabrics treated with different concentrations of PHMB solutions after dyeing with BPB dyebath

273 Establishment of linear relationship between colour strength and PHMB contents

Fig. 5 presents the increasing $K / S$ value associated with BPB dyeing of PHMBtreated cotton fabrics as the amount of adsorbed PHMB increases. A similar curve with adsorption isotherm of PHMB (Fig. 2) was observed, as shown in Fig. 5(a). The higher the quantity of PHMB adsorbed by cotton fabrics, the higher is the peak height of the $K / S$ spectrum achieved after being dyed with BPB dyebath. A drastic increase of the $K / S$ value is clearly observed with PHMB adsorption increasing from approximately $0.5 \mathrm{mg} / \mathrm{g}$ to $5 \mathrm{mg} / \mathrm{g}$, and then it levels up to around 15. This demonstrates that the colour strength $(K / S$ value) is proportional to the quantity of PHMB adsorbed on the fabrics at low concentrations, whereas at higher concentrations, the $K / S$ value shows a slow and fluctuating growth. The reason may be related to the conformation and arrangement of PHBM molecule on the surface of cotton fabrics (Fig. 6). At lower concentrations, PHMB molecules transport and adsorb from solution to the surface of cellulosic fibres in the form of monolayer loose distribution (Fig. 6a), and with the increasing concentrations, the looselyarranged PHMB aggregates form a densely-packed monolayer (Fig. 6b) (Blackburn RS et al. 2006). Afterwards, a multilayer stacking of PHMB molecules via reconfirmation on the surface of cellulosic fibres is formed with the outer layer changing from loosely-arranged to densely-packed, as the concentration of PHMB further increases (Fig. 6(c, d)). The dyeing primarily occurs between BPB and the loosely distributed PHMB molecules (Fig. 6(e, f, g)), and due to the steric hindrance effect, BPB molecules cannot bond with inner layer of colour strength $(K / S$ value $)$ as PHMB concentration increases beyond the critical monolayer capacity. From Fig. 5(a), the critical monolayer capacity of PHMB adsorption onto cellulosic fabrics is approximately $4.5 \mathrm{mg} / \mathrm{g}$, which by Blackburn et al. (2006). 

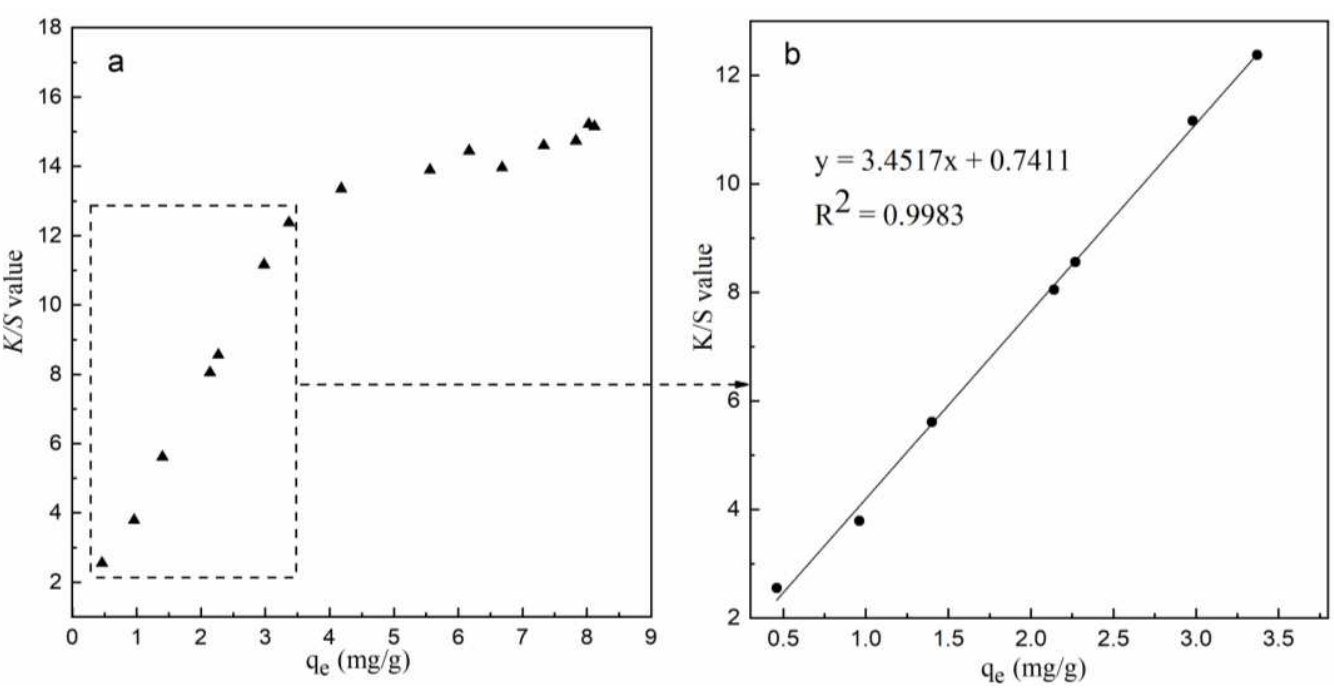

Fig. 5 Plot of $K / S$ values of BPB dyed cotton fabrics versus the amount of adsorbed PHMB (a); and (b) plot of $K / S$ values versus samples with low quantity of PHMB 306 adsorption (P1-P7)

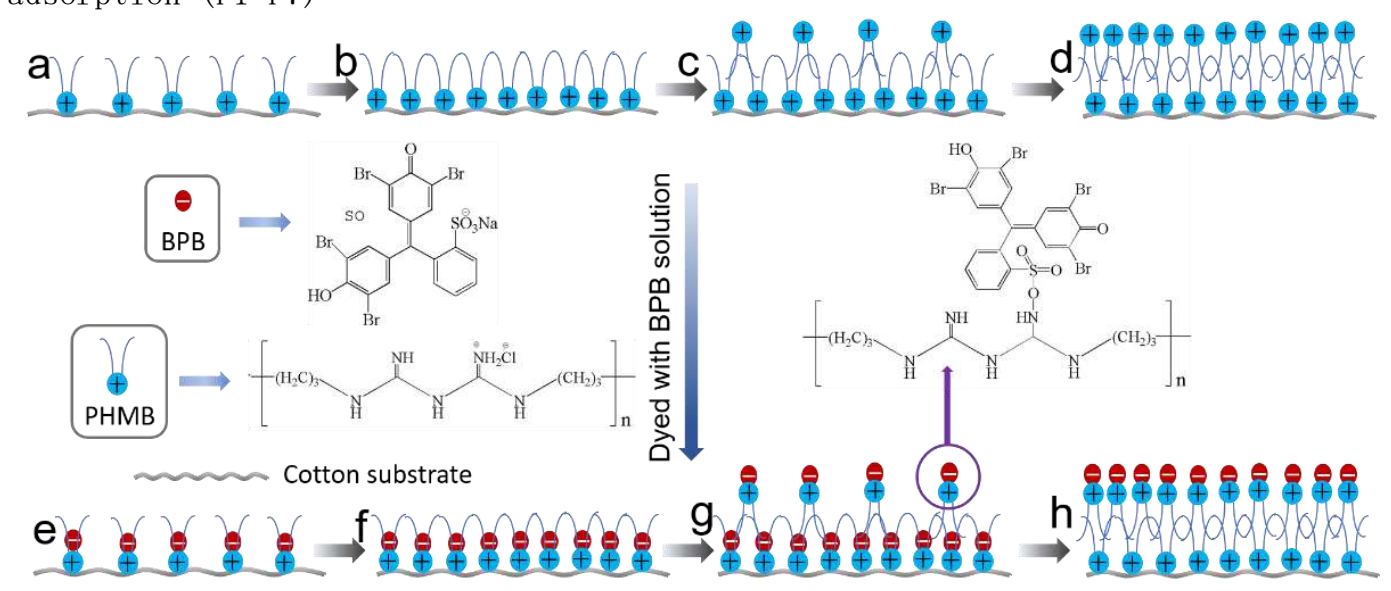

Fig. 6 Schematic diagram to show the arrangement of PHMB molecules adsorbed on the surface of cellulosic fibres and the dyeing behavior: (a) loose distribution; (b) dense distribution; (c) loose distribution of outer layer; (d) dense distribution of outer layer; (e) loosely-distributed PHMB dyed with BPB; (f) densely-distributed PHMB dyed with BPB; (g) loosely-distributed multilayer PHMB dyed with BPB; and (h) densely-distributed multilayer PHMB dyed with BPB Fig. $5(\mathrm{~b})$ shows a linear relationship between $K / S$ value and the quantity of PHMB adsorbed on the fabric at low concentrations. The high correlation $\left(R^{2}=0.9983\right)$ suggests that it is a promising and efficient way to quantify the PHMB coated on the fabrics by measuring the colour strength after being dyed with excess BPB dyebath. According to Eq. (2), the formula in Fig. 5(b) can be written as Eq. 5:

$$
K / S=3.4517 \times C(\mathrm{PHMB})+0.7411
$$

So, the quantity of PHMB adsorbed onto the cotton fabric substrate is given in Eq. (6) :

This equation should fulfill four requirements: (1) distribution of PHMB on

$$
C(\mathrm{PHMB})=\frac{\left(\frac{K}{S}-0.7411\right)}{3.4517}
$$
the surface of cotton fabric should be in the form of monolayer with content less than $5.3 \mathrm{mg} / \mathrm{g}$; (2) an excess of BPB dyebath should be applied; (3) dyeing 


\section{In vitro biosafety evaluation}

Biosafety is an important property for textiles which is imparted by proper finishing agents used for performance improvement such as antibacterial activity. Long-term exposure to textiles coated with excess of cytotoxic antibacterial agents may cause skin irritation and inflammation, particularly in case of the elderly and young children, as well as people with sensitive skin. In the present study, cytotoxicity of PHMB-coated cotton fabrics was evaluated by MTT assay according to IS0 10993-5:2009(E). MTT, a yellow watersoluble tetrazolium salt, can be reduced in viable cells to a blue-violet insoluble formazan. The number of viable cells correlates to the colour intensity which can be photometrically determined after the formazan is dissolved in alcohol. Therefore, MTT assay is commonly used for biosafety evaluation by measuring the cell viability. Fig. 7 shows the cell viability of cotton fabrics coated with different quantities of PHMB. The higher the cell viability, the lower is the cytotoxicity and the better is the biosafety of the tested samples.

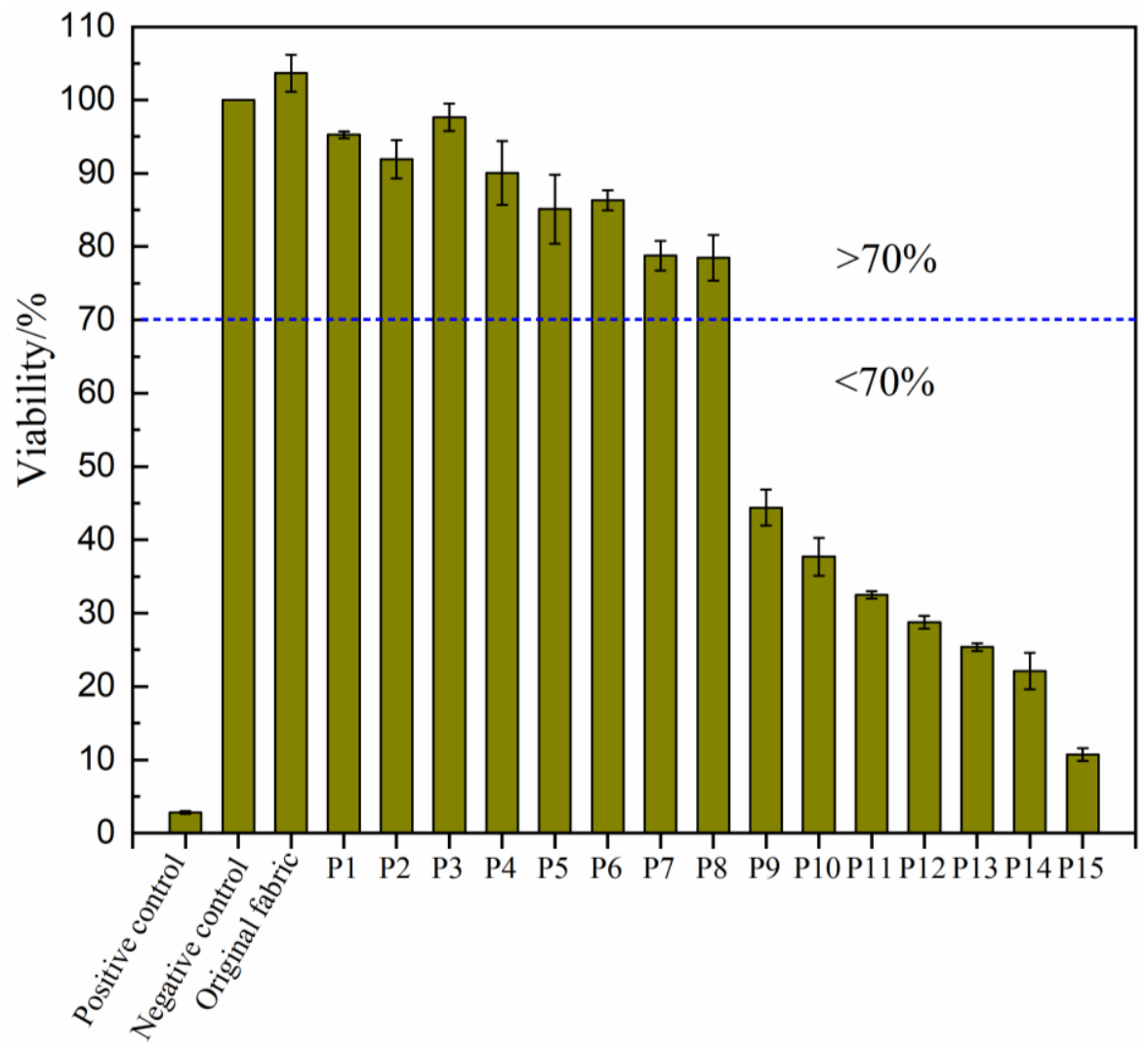

Fig. 7 In vitro cytotoxicity of coated cotton fabrics with different quantities of PHMB evaluated by MTT assay

As shown in Fig. 7, the positive control has a strong cytotoxicity with $2.8 \%$ viability of cells, whereas the sample of negative control is completely nontoxic, with $100 \%$ cell viability, as expected. Likewise, the untreated original cotton fabric is also non-toxic. However, it is worth noting that the average cell viability of the untreated original fabric is over $100 \%$, which means cells are reproduced after being cultured. This could explain why the cotton fabric is highly susceptible to microbial colonization and leads to deterioration of fibre strength and quality (Chauhan et al. 2019; Rong et al. 
2019). For fabric samples treated with antibacterial agent PHMB (P1-P15), a clear decrease in the number of viable cells was observed. The cell viability is basically inversely proportional to the PHMB content. The higher is the PHMB content, the lower the cell viability of the sample is. Moreover, there is a sharp decline in cell viability for sample P9, as compared to P8. As per the standard IS0 10993-5:2009(E), the sample should be considered noncytotoxic if the relative cell viability is greater than $70 \%$. Therefore, samples of P9-P15 can be considered cytotoxic, whereas the non-cytotoxic samples of P1-P8 are acceptable for safe use. On the other hand, the $K / S$ values of P8-P15 range from 13.2 to 15.2. Therefore, it was concluded that the sample can be considered cytotoxic if the $K / S$ value exceeds 13.2. Accordingly, the PHMB content for sample P8 $(4.62 \mathrm{mg} / \mathrm{g})$ can be regarded as the critical value for safe use, suggesting that the quantity of PHMB coated on cotton fabrics should not exceed $4.62 \mathrm{mg} / \mathrm{g}$ which falls within the range of the actual value $(4.5 \mathrm{mg} / \mathrm{g})$ and theoretical value $(5.3 \mathrm{mg} / \mathrm{g})$ of monolayer capacity for PHMB adsorbed onto cellulosic fibres. This could be explained by the fact that a multilayer stacking of PHMB molecules via reconfirmation could be formed on the surface of cellulosic fibres if the PHMB content exceeds the critical value $4.62 \mathrm{mg} / \mathrm{g}$ (Fig. 6(C, D)) (Einarson et al. 1991). PHMB molecules of the outer layer are more liable to dissociate from the PHMB molecules in the inner layer because Van der Waals' force between the hydrophobic moieties of PHMB molecules is weaker than the electrostatic attraction between PHMB molecules of inner layer and cellulosic molecules. The dissociated PHMB molecules are responsible for the cytotoxicity and antibacterial activity (Yuan and Cranston 2008; Simoncic and Tomsic 2010). Therefore, it is a reasonable conclusion that the quantity of PHMB coated on cotton fabrics should not exceed $4.62 \mathrm{mg} / \mathrm{g}$, and the sample can be considered cytotoxic if the $K / S$ value is greater than 13.2 .

\section{Conclusions}

Determination of quantity of cationic finishing agents on the surface of cotton fabrics is a challenge in textile industry. The present study employs PHMB as a model cationic agent to validate the assumption that quantifies cationic agents on the cotton fabrics, using Kubelka-Munk equation. The adsorption of PHMB onto cotton fabrics was first investigated and found to be concentration-dependent which increases with increase in the concentration of PHMB applied. The maximum adsorption of PHMB is around $8 \mathrm{mg}$ per gram of cotton fabric. After being dyed with BPB dyebath, a positive correlation was found between colour strength and the initial PHMB concentrations, particularly for the low concentration $(<2400 \mathrm{mg} / \mathrm{L})$. At high concentration $(>2400 \mathrm{mg} / \mathrm{L})$, colour strength increases slowly. A linear relationship with a high correlation $\left(\mathrm{R}^{2}=0.9983\right)$ between $K / S$ value and the adsorbed quantity of PHMB on the fabrics at low concentrations was established, as shown in Eq. (6), which could be used for determination of quantity of PHMB coated on the cotton fabrics. However, this equation should fulfill four requirements: (1) distribution of PHMB on the surface of cotton fabric should be in the form of monolayer with the content less than $5.3 \mathrm{mg} / \mathrm{g}$; (2) an excess of BPB dyebath should be applied; (3) the dyeing should come to equilibrium; and (4) the fabrics should be evenly dyed. Furthermore, MTT assay demonstrates that the quantity of PHMB coated on cotton fabrics should not exceed $4.62 \mathrm{mg} / \mathrm{g}$, and the sample is considered non-cytotoxic if the $K / S$ value is lower than 13.2. 
In summary, the present study reports a direct and feasible method to determine the quantity of PHMB on cellulosic textile fabrics by Kubelka-Munk equation, which may provide an enlightening guidance for a quantitative assay of cationic finishing agents on cellulosic fabrics.

Acknowledgement

The authors gratefully appreciate financial support from The Hong Kong Polytechnic University for this work under the project of account code: ZVNM and ZVQJ.

\section{Conflicts of interest}

The authors declare they have no financial interests.

Reference

Agarwal G, Perwuelz A, Koeh1 L, Lee KS (2011) Interaction between the Surface Properties of the Textiles and the Deposition of Cationic Softener. J Surfactants Deterg 15: 97-105. https://doi.org/10.1007/s11743-011-1273-4

Ahmed N, Oulton DP, Taylor JA (2006) The use of reflectance measurements in the determination of fixation of reactive dyes to cotton. Color Res Appl 31: 117-21. https://doi.org/10.1002/col.20189

Beal CM, 01son LA, Wentz M (1990) Property modifications of finished textiles by a cationic surfactant. J Am 0il Chem Soc 67: 689-97. https://doi.org/10. 1007/BF02540424

Becerir B (2005) A novel approach for estimating the relation between $\mathrm{K} / \mathrm{S}$ value and dye uptake in reactive dyeing of cotton fabrics. Fiber Polym 6: 224-28. https://doi.org/10. 1007/BF02875646 Blackburn RS, Harvey A, Kettle LL, Payne JD, Russel1 SJ (2006) Sorption of poly (hexamethylenebiguanide) on cellulose: mechanism of binding and molecular recognition. Langmuir 22: 5636-44. D0I: $10.1021 / 1 \mathrm{a} 053002 \mathrm{~b}$

Brunon C, Bessueille F, Carol G et al (2011) ToF-SIMS and XPS characterization of antimicrobial textiles for the food processing industry. Surf Interface Anal 43: 604-08. https://doi.org/10. 1002/sia. 3654

Chauhan P, Kumar A, Bhushan B (2019) Self-cleaning, stain-resistant and anti-bacterial superhydrophobic cotton fabric prepared by simple immersion technique. J Colloid Interface Sci 535: 66-74. https://doi.org/10.1016/j. jcis.2018.09.087

Colichman EL (1947) Photocolorimetric method for determination of quaternary ammonium salts. Analytical Chemistry 19: 430-31. https://doi.org/10.1021/ac60006a023

De Paula GF, Netto GI, Mattoso LHC (2011) Physical and Chemical Characterization of Poly(hexamethylene biguanide) Hydrochloride. 
448 Polymers 3: 928-41. https://doi.org/10.3390/polym3020928

449 Einarson M, Rein A, Lars Ö, Berg JC (1991) Adsorption and 450 reconformation of a series of cationic polyacrylamides on charged 451 surfaces. Colloids and Surfaces 53: 183-91.

452 https://doi.org/10.1016/0166-6622(91) 80044-0

453 Fan QG (2005) Chemical testing of textiles. Woodhead Publishing and 454 CRC Press.

455 Funaki A, Horikoshi Y, Kobayashi T, Masadome T (2020) Determination 456 of Polyhexamethylene Biguanide Hydrochloride Using a Lactone457 Rhodamine B-Based Fluorescence 0ptode. Molecules 25. 458 https://doi.org/10.3390/molecules25020262

459 Gao DG, Li XJ, Li YJ, Lyu B, Ren JJ, Ma JZ (2021) Long-acting 460 antibacterial activity on the cotton fabric. Cellulose. 461 https://doi.org/10.1007/s10570-020-03560-5

462 Gao DG, Li YJ, Lyu B, Jin DN, Ma JZ (2019) Silicone quaternary 463 ammonium salt based nanocomposite: a long-acting antibacterial 464 cotton fabric finishing agent with good softness and air 465 466 467 Gargoubi S, Tolouei R, Chevallier P, Levesque L, Ladhari N, 468 Boudokhane C, Mantovani D (2016) Enhancing the functionality of 469 cotton fabric by physical and chemical pre-treatments: A comparative 470 study. $\quad$ Carbohyd $\quad$ Polym 147: 28-36. 471 https://doi.org/10.1016/j. carbpo1.2016.03.084

472 Khatri A, White M, Padhye R, Momin NH (2014) The use of reflectance 473 measurements in the determination of diffusion of reactive dyes 474 into cellulosic fiber. Color Res App1 39: 63-69. 475 https://doi.org/10.1002/col.21764

476 Kosswig K (2000) Surfactants. In: Wiley-VCH (ed) U1lmann's 477 Encyclopedia of Industrial Chemistry. Wiley-VCH, pp. 431-501

478 Li ST, Zhao SL (2004) Spectrophotometric determination of cationic 479 surfactants with benzothiaxolyldiazoaminoazobenzene. Analytica 480 Chimica Acta 501: 99-102. https://doi.org/10. 1016/j. aca.2003.09.014 481 Li ZH, Wang HJ, Chen ZJ (2019) Monitoring and modulation of insulin 482 fibers by a protein isomerization targeting dye bromophenol blue. 483 Sensors and Actuators B: Chemical 287: 496-502. 484 https://doi.org/10.1016/j.snb.2019.02.071

485 Lucas AD, Gordon EA, Stratmeyer ME (2009) Analysis of 486 polyhexamethylene biguanide in multipurpose contact lens solutions. 487 Talanta 80: 1016-9. https://doi.org/10.1016/j.talanta.2009.07.031 488 Masadome T, Oguchi S, Kobayashi T, Hattori T (2018) Flow injection 489 spectrophotometric determination of polyhexamethylene biguanide 490 hydrochloride in contact-lens detergents using anionic dyes. Curr. 491 Anal. Chem. 14: 446-51. D0I : 10.2174/1573411013666171117162909 492 Mitchel1 R, Carr CM, Parfitt M, Vickerman JC, Jones C (2005) Surface 
493 chemical analysis of raw cotton fibres and associated materials.

494 Cellulose 12: 629-39. https://doi.org/10. 1007/s10570-005-9000-9

495 Motomizu S, Gao YH (1994) Solvatochromism based on the interaction

496 between azo dyes and hydrophobic ions: application to the

497 determination of surfactants by flow-injection spectrophotometry.

498 Microchem. J. 49: 326-39.

499 https://doi.org/10.1006/mchj.1994.1044

500 Rong L, Liu H, Wang B, Mao Z, Xu H, Zhang L, Zhong Y, Feng X, Sui

$501 \quad X$ (2019) Durable antibacterial and hydrophobic cotton fabrics

502 utilizing enamine bonds. Carbohydr Polym 211: 173-80.

503 https://doi.org/10.1016/j. carbpo1.2019.01.103

504 Sheiham I, Pinfold TA (1969) The spectrophotometric determination

505 of cationic surfactants with picric acid. Analyst 94: 387-88.

506 https://doi.org/10.1039/AN9699400387

507 Simoncic B, Tomsic B (2010) Structures of Novel Antimicrobial Agents

508 for Textiles - A Review. Text Res J 80: 1721-37.

509 https://doi.org/10.1177/0040517510363193

510 Sivaramakrishnan CN (2013). The use of surfactants in the finishing

511 of technical textiles. In Gulrajani M. L. (ed) Advances in the Dyeing

512 and Finishing of Technical Textiles. Woodhead Publishing, pp. 199-

$513 \quad 235$

514 Tang AYL, Lee CH, Wang YM, Kan CW (2019) A study of PEG-based

515 reverse micellar dyeing of cotton fabric: reactive dyes with

516 different reactive groups. Cellulose 26: 4159-73.

517 https://doi.org/10.1007/s10570-019-02340-0

518 Uematsu K, Akihito S, Hajime K (2019) Determination of

519 polyhexamethylene biguanide utilizing a glucose oxidase enzymatic

520 reaction. Anal. Sci. 35: 1021-25.

521 https://doi.org/10.2116/analsci.19P095

522 Wågberg L, Ödberg L, Lindström T, Aksberg R (1988) Kinetics of

523 adsorption and ion-exchange reactions during adsorption of cationic

524 polyelectrolytes onto cellulosic fibers. Colloids and Surfaces 31:

525 119-24. https://doi.org/10. 1016/0166-6622(88)80187-2

526 Wang WY, Chiou JC, Yip J, Yung KF, Kan CW (2020) Development of

527 Durable Antibacterial Textile Fabrics for Potential Application in

528 Healthcare Environment. Coatings 10: 520.

529 https://doi.org/10.3390/coatings 10060520

530 Wang WY, Kan CW (2020) An eco-friendly dyeing method: bromophenol

531 blue (BPB) applied for dyeing cotton fabrics coated with cationic

532 finishing agents. Cellulose: $9045-59$.

533 https://doi.org/10.1007/s10570-020-03375-4

534 Wang X, Zhang J, Wang Y, Liu Y, Li Z, Xie Z, Chen Z (2017)

535 Fluorescent Protein Nanovessels: A New Platform to Generate Bio-

536 Abiotic Hybrid Materials for Bioimaging. Adv Funct Mater 27.

537 https://doi.org/10.1002/adfm. 201702051 
538 Yuan G, Cranston R (2008) Recent Advances in Antimicrobial 539 Treatments of Textiles. Text Res J 78: 60-72.

540 https://doi.org/10.1177/0040517507082332

541 
542 Fig. 1 The maximum absorbance of PHMB solution over the UV-vis spectrum (A); and 543 the calibration curve of PHMB solution established at $235 \mathrm{~nm}$ (B)

544 Fig. 2 Adsorption of PHMB onto the cotton fabric with concentration ranging from $545100 \mathrm{mg} / \mathrm{L}$ to $10000 \mathrm{mg} / \mathrm{L}$

546 Fig. 3 Colour shades of PHMB-treated cotton fabrics after dyed with BPB dyebath

547 Fig. 4 Colour strength curves of cotton fabrics treated with different 548 concentrations of PHMB solutions after dyeing with BPB dyebath

549 Fig. 5 Plot of $K / S$ values of BPB dyed cotton fabrics versus the amount of adsorbed 550 PHMB (A); and (B) plot of $K / S$ values versus samples with low quantity of PHMB 551 adsorption (P1-P7)

552 Fig. 6 Schematic diagram to show the arrangement of PHMB molecules adsorbed on 553 the surface of cellulosic fibres and the dyeing behavior: (A) loose distribution; 554 (B) dense distribution; (C) loose distribution of outer layer; (D) dense 555 distribution of outer layer; (E) loosely-distributed PHMB dyed with BPB; (F) 556 densely-distributed PHMB dyed with BPB; $(G)$ loosely-distributed multilayer PHMB 557 dyed with BPB; and (H) densely-distributed multilayer PHMB dyed with BPB

558 Fig. 7 In vitro cytotoxicity of coated cotton fabrics with different quantities 559 of PHMB evaluated by MTT assay

560 Table 1 Sample list for cotton fabrics coated with different concentrations of 561 PHMB 
Figures
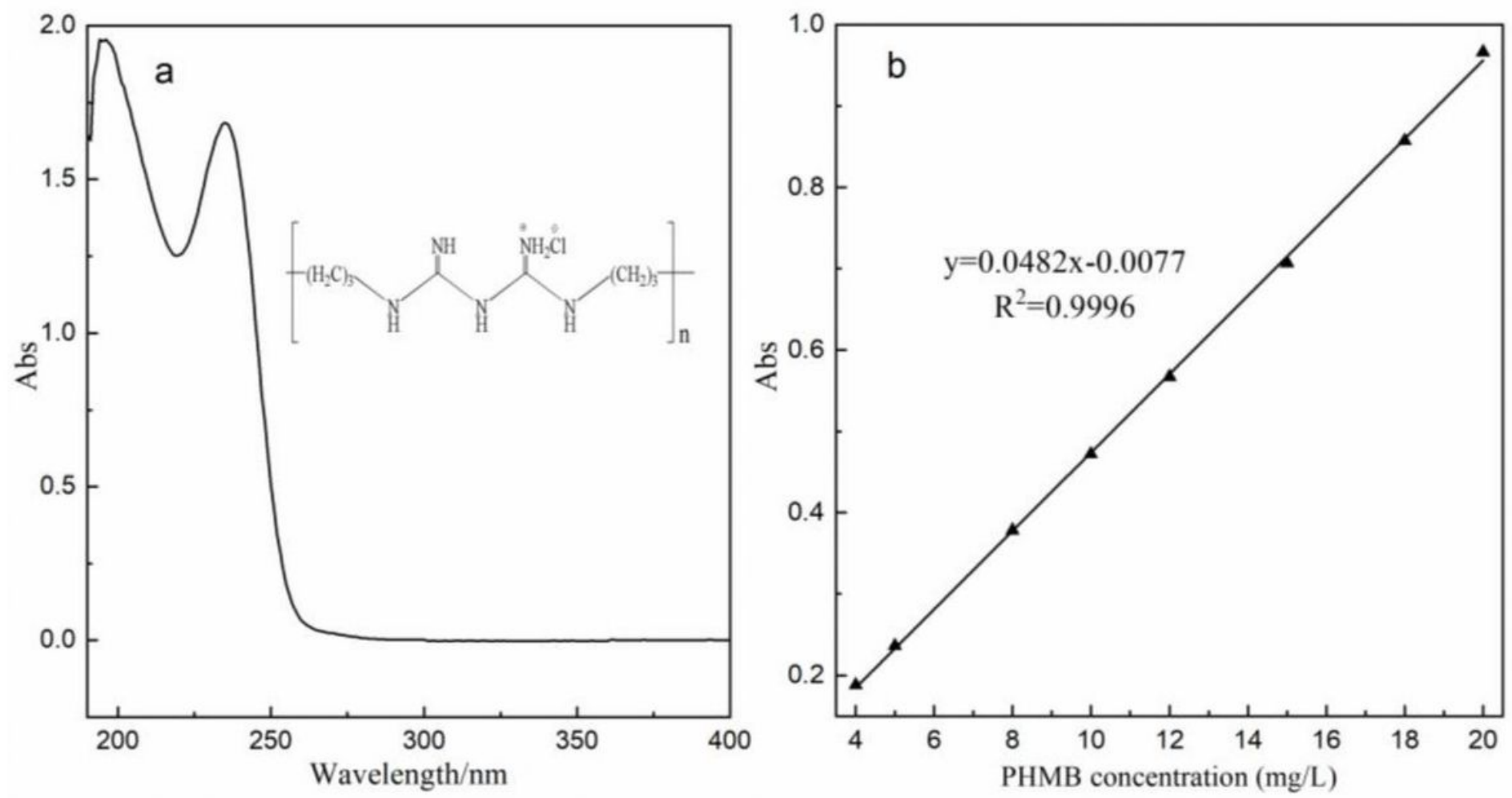

Figure 1

The maximum absorbance of PHMB solution over the UV-vis spectrum (a); and the calibration curve of PHMB solution established at $235 \mathrm{~nm}$ (b) 


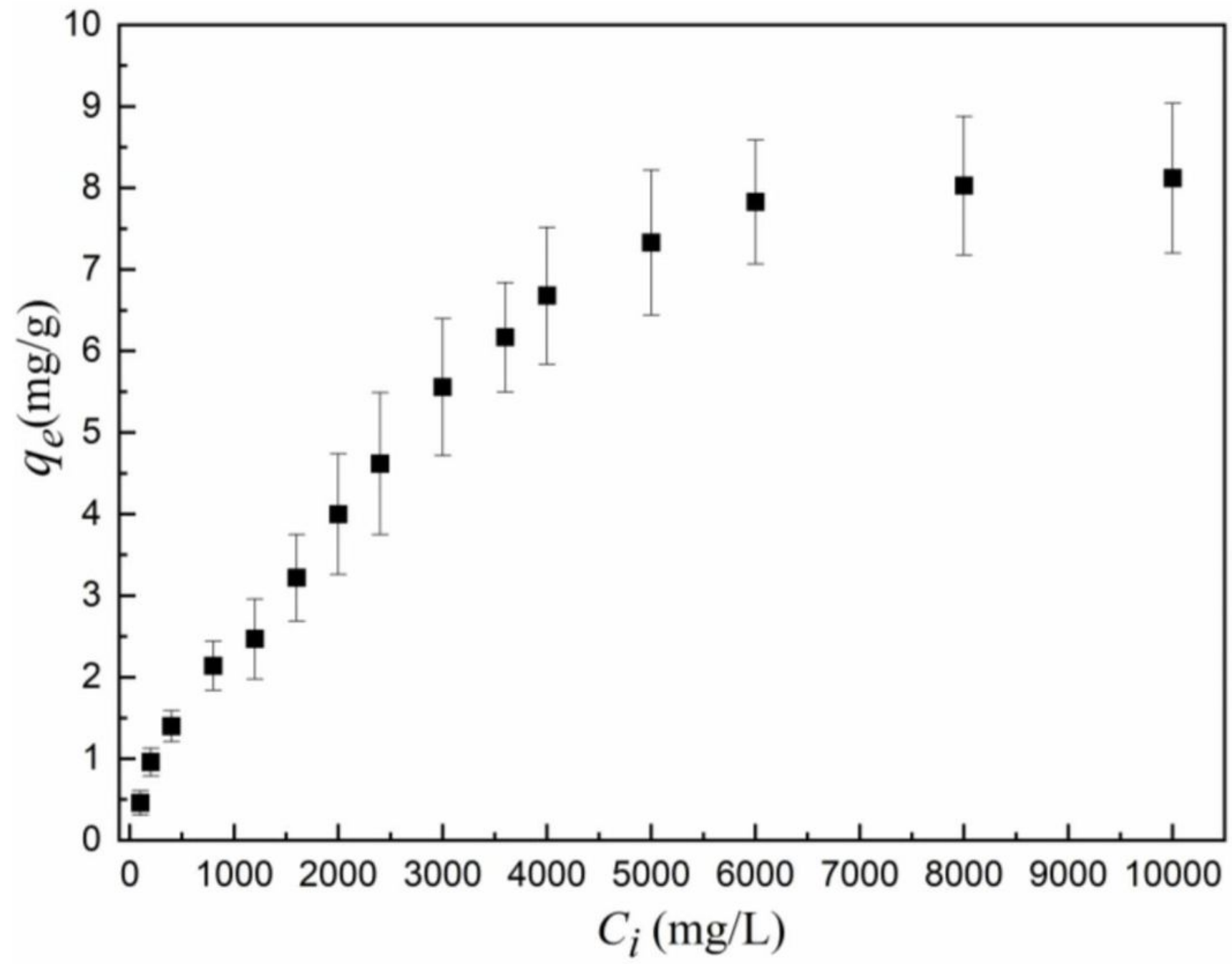

Figure 2

Adsorption of PHMB onto the cotton fabric with concentration ranging from $100 \mathrm{mg} / \mathrm{L}$ to $10000 \mathrm{mg} / \mathrm{L}$ 

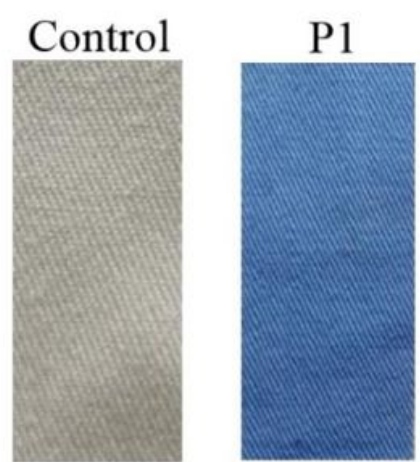

P8
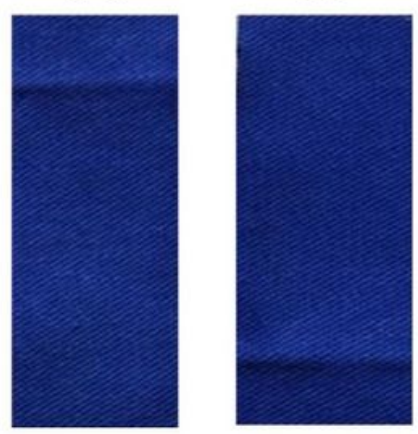

P2

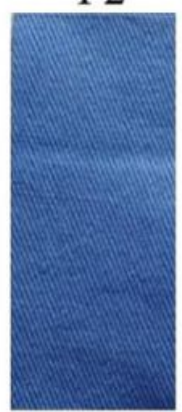

P10

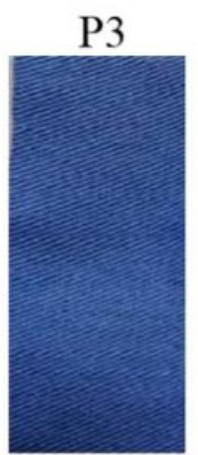

P11
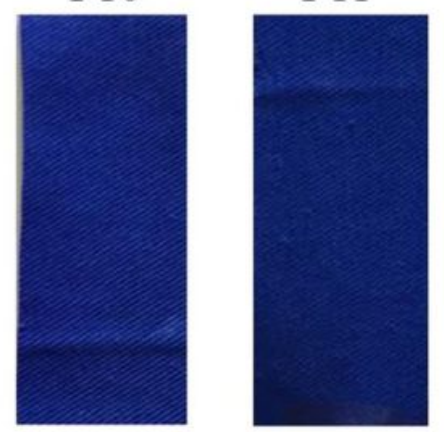

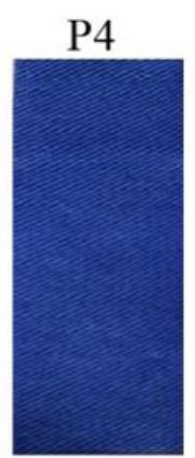

$\mathrm{P} 12$

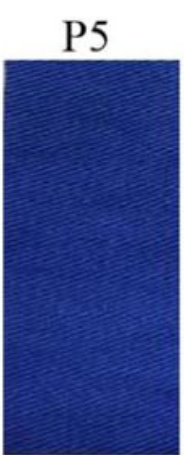

P13

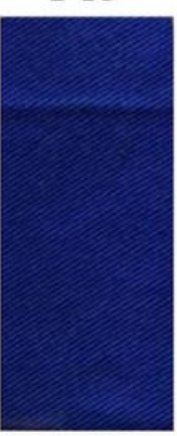

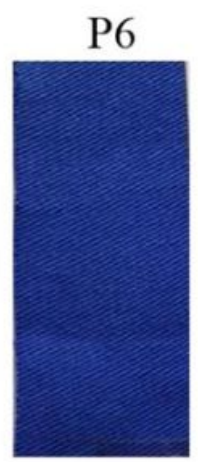

P14

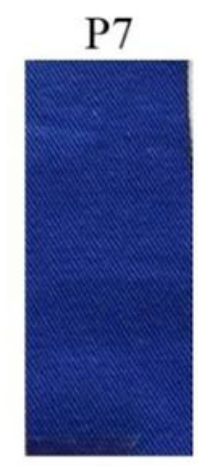

P15
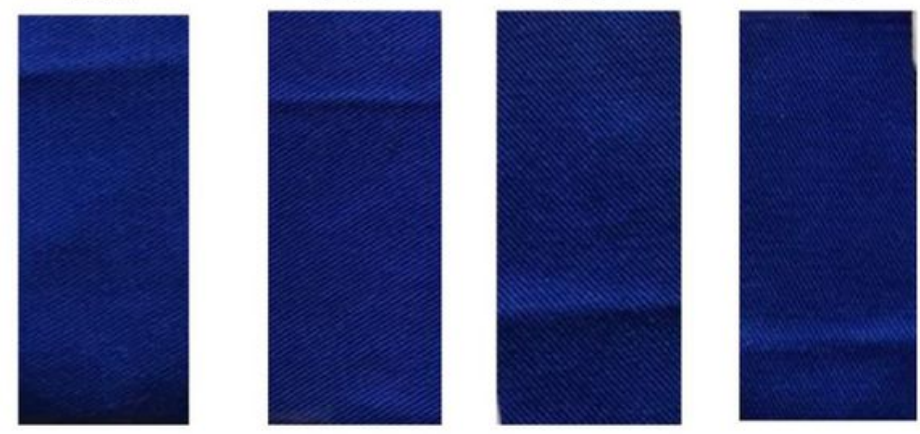

Figure 3

Colour shades of PHMB-treated cotton fabrics after dyed with BPB dyebath 


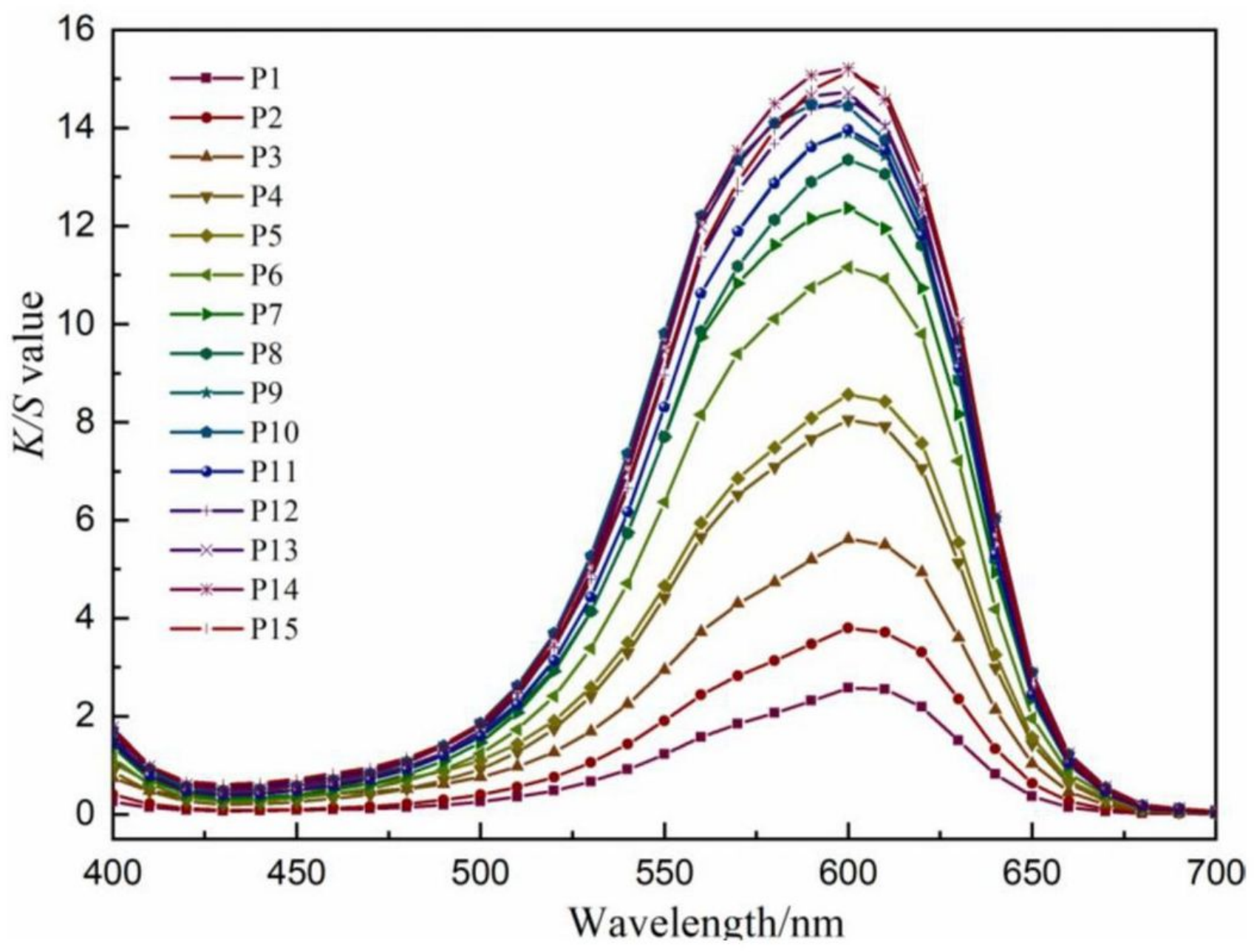

Figure 4

Colour strength curves of cotton fabrics treated with different concentrations of PHMB solutions after dyeing with BPB dyebath 

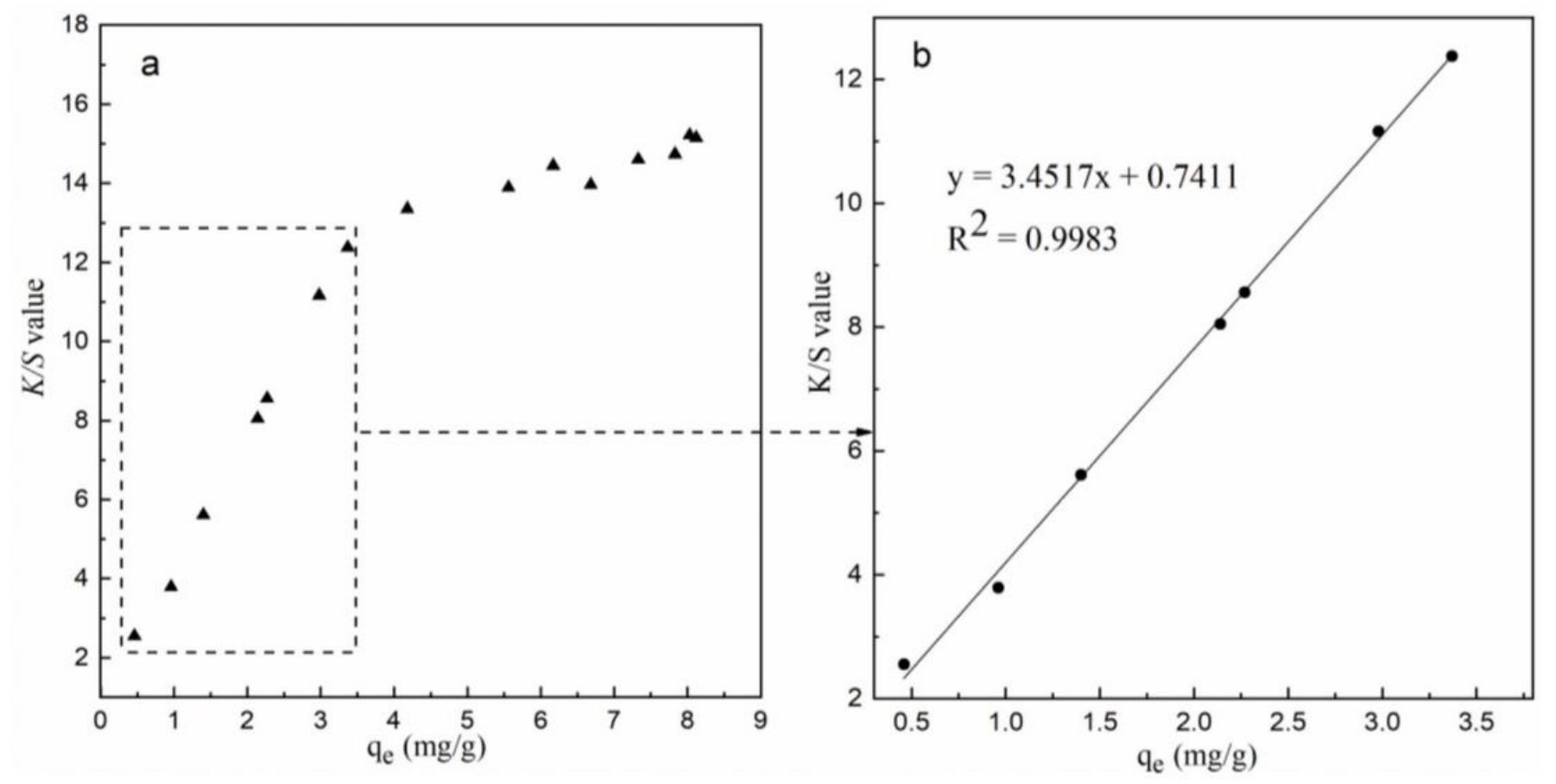

Figure 5

Plot of K/S values of BPB dyed cotton fabrics versus the amount of adsorbed PHMB (a); and (b) plot of $\mathrm{K} / \mathrm{S}$ values versus samples with low quantity of PHMB adsorption (P1-P7)

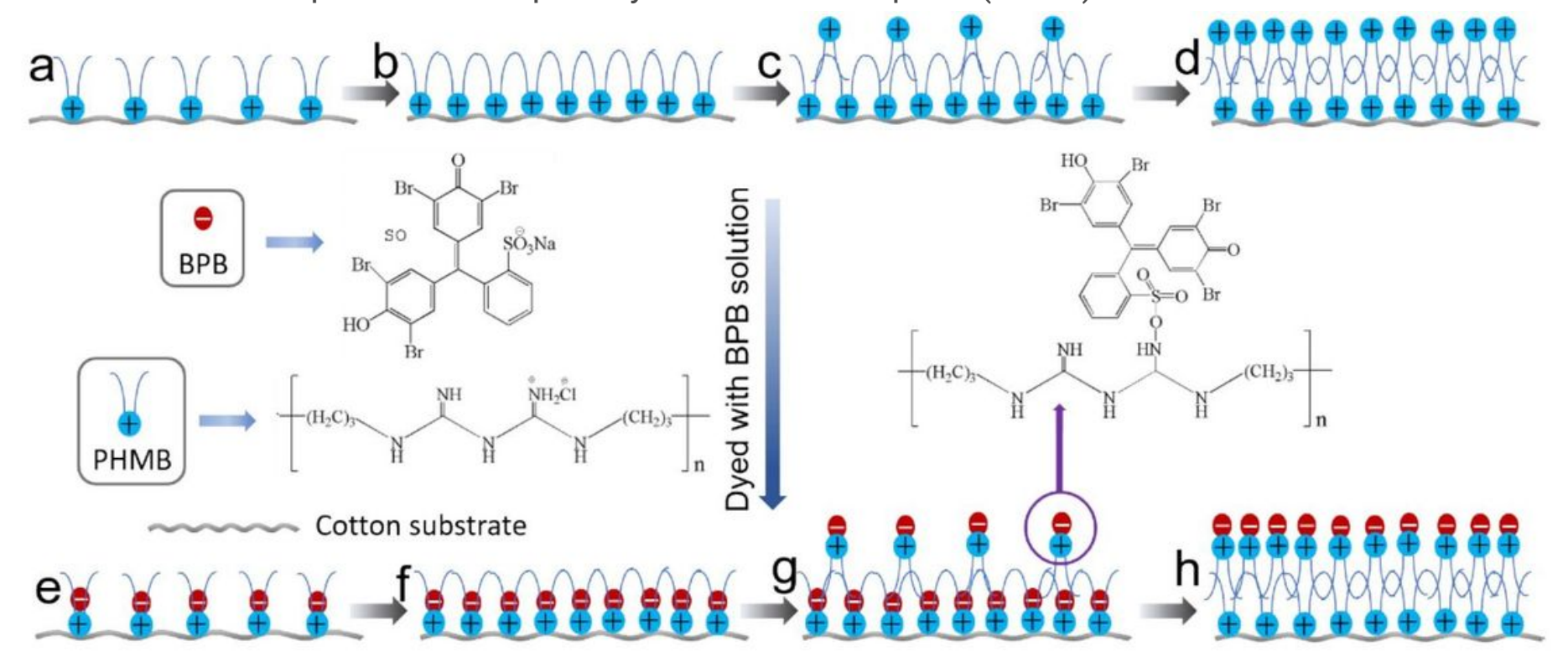

Figure 6

Schematic diagram to show the arrangement of PHMB molecules adsorbed on the surface of cellulosic fibres and the dyeing behavior: (a) loose distribution; (b) dense distribution; (c) loose distribution of outer layer; (d) dense distribution of outer layer; (e) loosely-distributed PHMB dyed with BPB; (f) densely- 
distributed PHMB dyed with BPB; (g) loosely-distributed multilayer PHMB dyed with BPB; and (h) denselydistributed multilayer PHMB dyed with BPB

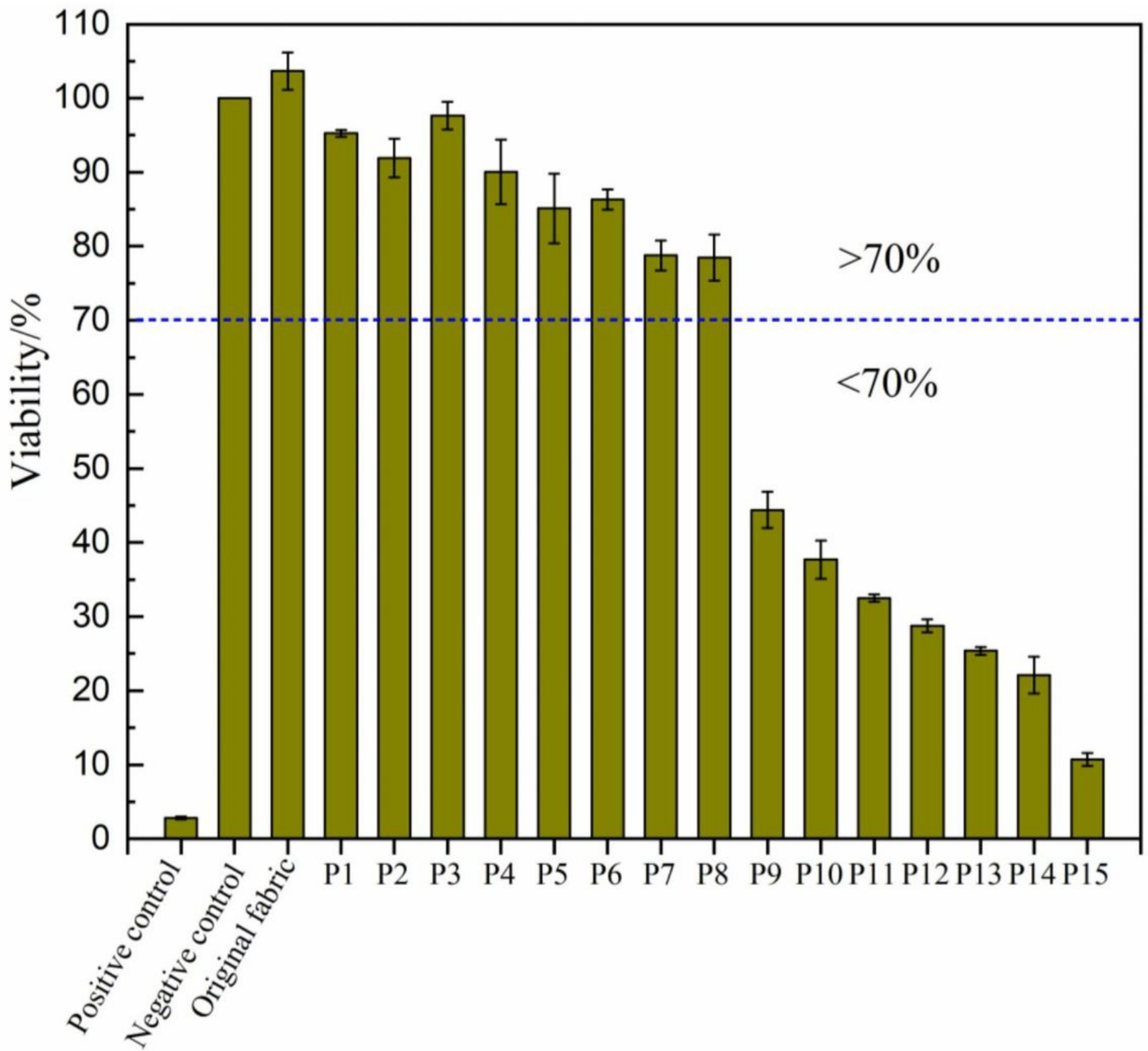

Figure 7

In vitro cytotoxicity of coated cotton fabrics with different quantities of PHMB evaluated by MTT assay 